\title{
THE TIPULID HYPOPYGIUM, A STUDY IN SPECIFIC
}

\section{ADAPTATIONS.}

\section{BY ROBERT. E. SNODGRASS, STANFORD UNIVERSITY, CAL.}

A detailed study of the terminal abdominal segments of the males and females of the Tipulidae shows an enormous amount of variety in the hypopygial parts of the males, and, in striking contrast, a uniform simplicity of structure in the corresponding parts of the females. 'The writer has made such a study on a large number of Tipulid species in the entomological collection of the Washington Agricultural College, identified by Mr. R. W. Doane. The detailed descriptions and figures are comprised in two papers not yet published, but some facts of general interest are here given.

The term "hypopygium" may be most conveniently limited to the ninth abdominal segment of the male. This is the genital segment, $i$. e., the one that in all insects carries the intromittent organ and usually the clasping appendages.

The Tipulid hypopygium is in general cup-shaped with the opening posterior. The cavity of the cup is the genital chamber and is produced simply by the invagination of the posterior face of the segment. This necessarily carries into the genital chamber the tenth or anal segment which, morphologically, terminates the abdomen. Attached to the posterior rim of the hypopygium are, on each side, from one to three clasping lobes, called the apical appendages. The body of the segment is composed of four plates - one dorsal, one ventral, and two lateral. The dorsal and ventral plates are evidently the tergum and sternum respectively, while the lateral ones may be termed the pleural plates on account of their position. In the lower genera they have strictly a pleural position, but in the higher genera they may be simply set into the posterior rim of the segment, or exserted upon the posterior margin, or they may be lacking entirely. They always, however, when present, bear the apical appendages. According to the structure of the pleura the relationships of the larger groups within the family and the evolution of the genera from one another may be nicely traced.

Within the genital chamber and arising from its floor or anterior wall lies the penis, a straight or curved rod-like tube. Its terminal part is always protected by a chitinous guard arising from the posterior part of the floor of the genital chamber.

Now, although the larger groups within the family are separable on a basis of modifications in the more fundamental parts of the hypopygium, the other parts, such as the apical lobes, the penis, and the guard of the penis, present an infinite number of specific variations. No two species, no matter how similar otherwise, were found to be even nearly identical in the structure of these parts. 
Turning now to the females we find less variety in the terminal parts of the abdomen throughout the entire family than may characterize the males of one genus. The female parts are constructed as follows: The eighth sternum is prolonged far back of the eighth tergum, and is terminated by two elongate appendages set on edge beside each other. The ninth segment is much smaller in diameter than the eighth, and consists of a narrow ring of chitin. The tenth segment is generally elongate and terminates in two usually long and tapering cerci. The dorsal side of the eighth sternum is concave and the concavity is covered above by the ventral parts of the ninth and tenth segments. Rudimentary gonapophyses are present in the form of small plates or bars of chitin on the upper side of the eighth sternum and on the opposed ventral side of the ninth.

Within the group Tipulina the female genital parts differ almost exclusively in the form of the rudimentary gonapophyseal plates, and usually only the tips of these project as free processes. On the other hand, the modifications of the male parts within this group are excessive. Within the other groups the genera are characterized by slightly varying shapes of the external female parts, but in none is there any variety comparable with that existing between the males.

In other words, it is impossible to point out any correlation between the great variations of the male hypopygia and the extremely slight modifications of the female genitalia. How, then, are we to explain the origin of the former? If the modifications in the structure of the body of the hypopygium, the varieties in size and shape of the guard of the penis and the clasping apical appendages are not adaptive, why do they exist? The conclusion seems to be unavoidable that some other cause for specific variety must be operative here than that of adaptation to the female organs. That the more fundamental modifications of the hypopygium had an early origin in the evolution of the family is evinced by the fact that they are characteristic of the larger groups into which the family has been separated on other characters.

It is such a common method of explanation in the case of specific variations such as one meets with in these Tipulid hypopygia, to assume that they are adaptive, that it is interesting to see how such explanations may fail to be substantiated when tests are actually made. It can, of course, be said that our knowledge of the physiology of the parts is insufficient, and that on this account nicely balanced interrelations are not perceived. A failure to disprove, however, is not a proof of the opposite, and no one can ever say of anything that his knowlenge of it is complete. 

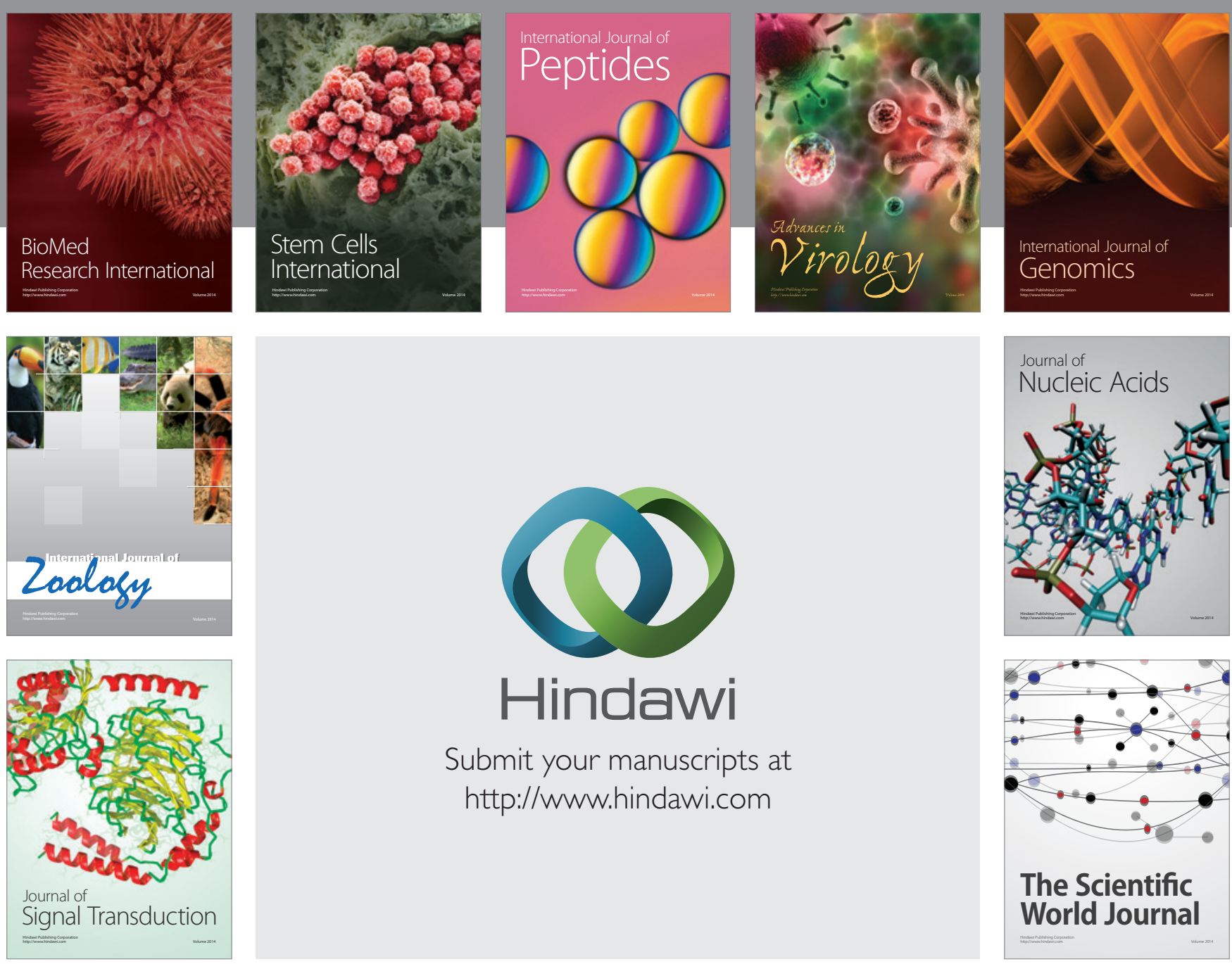

Submit your manuscripts at

http://www.hindawi.com
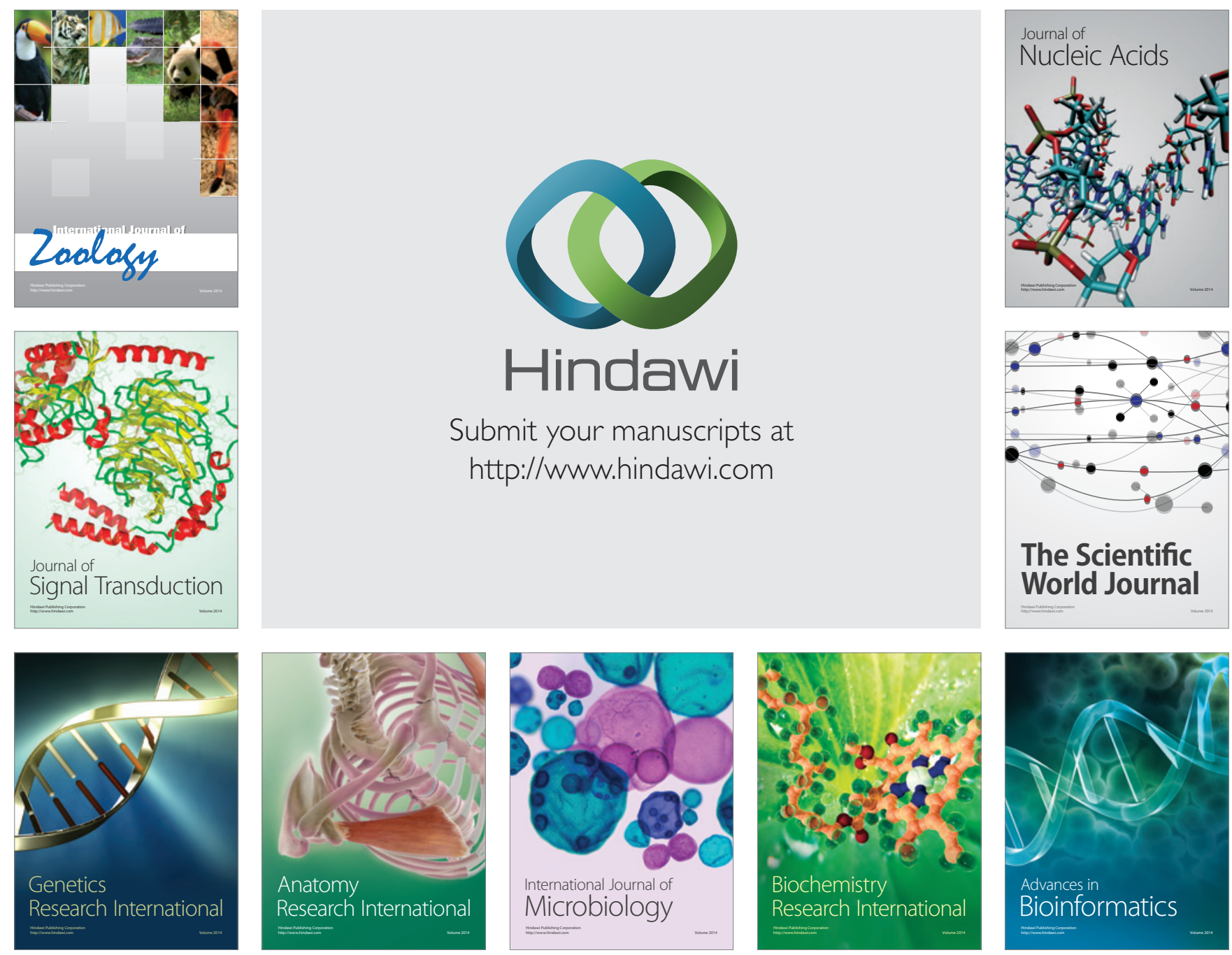

The Scientific World Journal
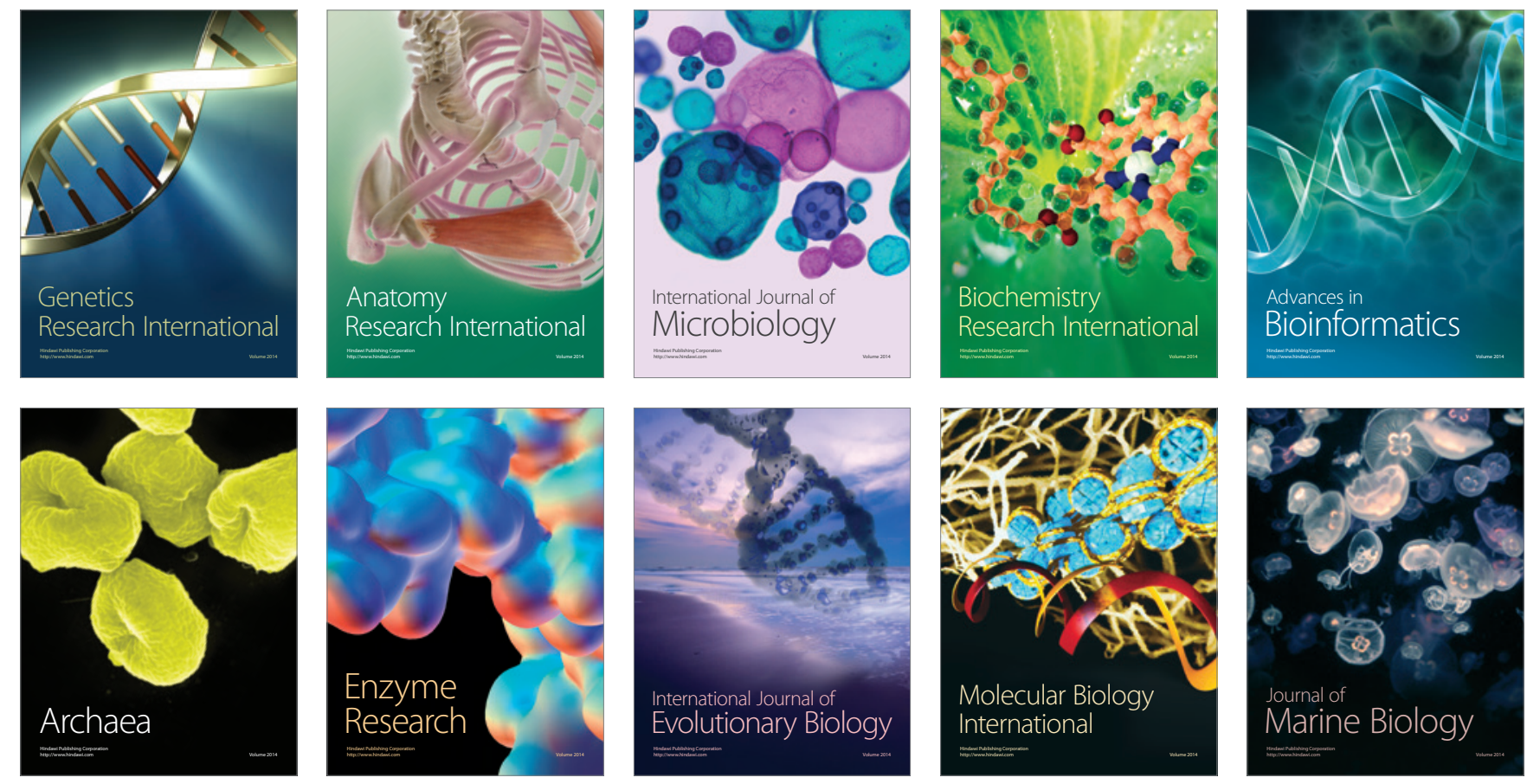